\title{
A Brief Note on Transcription, Yapese Orthography, and Data Collection
}

There have been a number of different orthographies used for Yapese. I have chosen to rely upon the orthography that has been adopted by the Yap State Department of Education. One drawback in using this orthography is that it does not always match up with Jensen's (1977a) dictionary or with the various ethnographies that I cite throughout the book. A very important advantage, however, is that it is the orthography that is being currently taught in Yapese schools.

As Elinor Ochs (1979) has argued, transcription practices are theory laden. The choices we make regarding what aspects of talk and interaction are represented through textual means are inescapably a reflection of our own analytical and interpretive interests. Such choices, in turn, do much to shape the form in which our observations take. In this book I have chosen to follow two very different approaches to transcribing my data that align with two different analytic aims.

Throughout most of the book I present individual narratives in terms of a free translation of the original Yapese. That is, I have chosen not to provide the original Yapese in interlineal translation. This is due to the fact that my analytical interests are focused more centrally on exploring the overarching content of individual narratives and the way in which painful experiences are both personally and culturally configured within them. This strategy for representing talk is, of course, much more familiar to cultural and psychological anthropologists.

In a few different sections of the book (in particular chapter 8) I provide in contrast a microanalytic examination of much more delimited stretches of talk and interaction. This data is drawn primarily from 
videotaped interactions between a local healer and one of her patients. Given my microanalytic focus, these transcripts more closely approximate forms that linguistic anthropologists are familiar with. The transcription conventions used in these cases were slightly modified from those proposed by Sacks, Schegloff, and Jefferson (1974) in one of their seminal papers on conversation analysis. They are as follows:

((sits down) ) Material between double parentheses provides extralinguistic information, such as gestures, bodily movements, positioning, etc., as well as paralinguistic information such as volume.

(pain) Words between parentheses in the English translation indicate information that is understood by native speakers but not explicitly stated in the Yapese morphemes. Question marks inside of parentheses mark inaudible talk. Square bracket between turns indicates a point where one speaker overlaps with another.

Three dots indicate an untimed pause in speech.

F; Initials for speakers are separated from their utterances by semicolons.

All told, the data collected for this book includes sixty-five interviews with thirty chronic pain sufferers (each interview was conducted in Yapese and ranged anywhere from thirty minutes to four hours in length), videotaped healing sessions (over thirty hours' worth), and observed healing sessions between local healers and fifteen chronic and acute pain sufferers, as well as twenty-five successive pile sorts that focused on the categorization of a number of Yapese terms for internal states. In addition, I was able to conduct four months of research at the Yap State Archives going through all of the attorney general's correspondences as well as all of the local periodicals printed in Yap since the I950s. In these records and periodicals I found much important information pertaining to a more general understanding of some key Yapese cultural values. It was also through my archival research that I was able to gain a better sense of the history of a number of social, legal, and health-related concerns from the perspective of the state government.

Furthermore, I had the opportunity to conduct two weeks of research at the Micronesian Area Research Center (MARC) at the University of Guam in January 2003. There I had access to one of the world's largest libraries and archival collections devoted specifically to 
Micronesian cultures and history. Through my research at MARC I obtained copies of a number of important collections of Yapese mythology as well as documents from a number of early ethnologists and merchants who either lived on or visited the island in the nineteenth and twentieth centuries. Finally, at the request of the village I lived in, my colleague Jennifer Dornan and I conducted a four-week GPS mapping and oral-history project. While not directly related to the goals of my study, the information I gathered about the history of various house foundations and past political alliances in the village contributed significantly to developing my current understanding of how the experience of pain fits into broader cultural frames associated with the significance of work, endurance, effort, and suffering as core virtues in Yapese society. Other interviews conducted for the study included conversations with the attorney general of Yap State, the head linguist for Yap State's Department of Education, the director of Yap State Public Health, three members of the mental health program at the state hospital, one of the hospital's doctors, and the doctor who runs the only private health clinic on the island.

With my archival research, the oral history and mapping project, the successive pile sorting tasks, and my everyday conversations and observations living in a Yapese household and community for what amounted to fifteen months spread out between the years of 2000 and 2005 , I believe that I was taught much about a number of core cultural virtues that importantly inform the ways in which individual sufferers sought to give meaning to their experiences of pain. In addition, by conducting interviews in conjunction with videotaping interactions between local healers and their patients, I was able to collect data that reflects both retrospective accounts of past experiences of pain in the context of particular life histories and naturally occurring discourse and interaction surrounding the real-time experiencing of dysphoric moments. With the exception of individuals listed in the acknowledgments, all other names used in this book are pseudonyms. 
This page intentionally left blank 


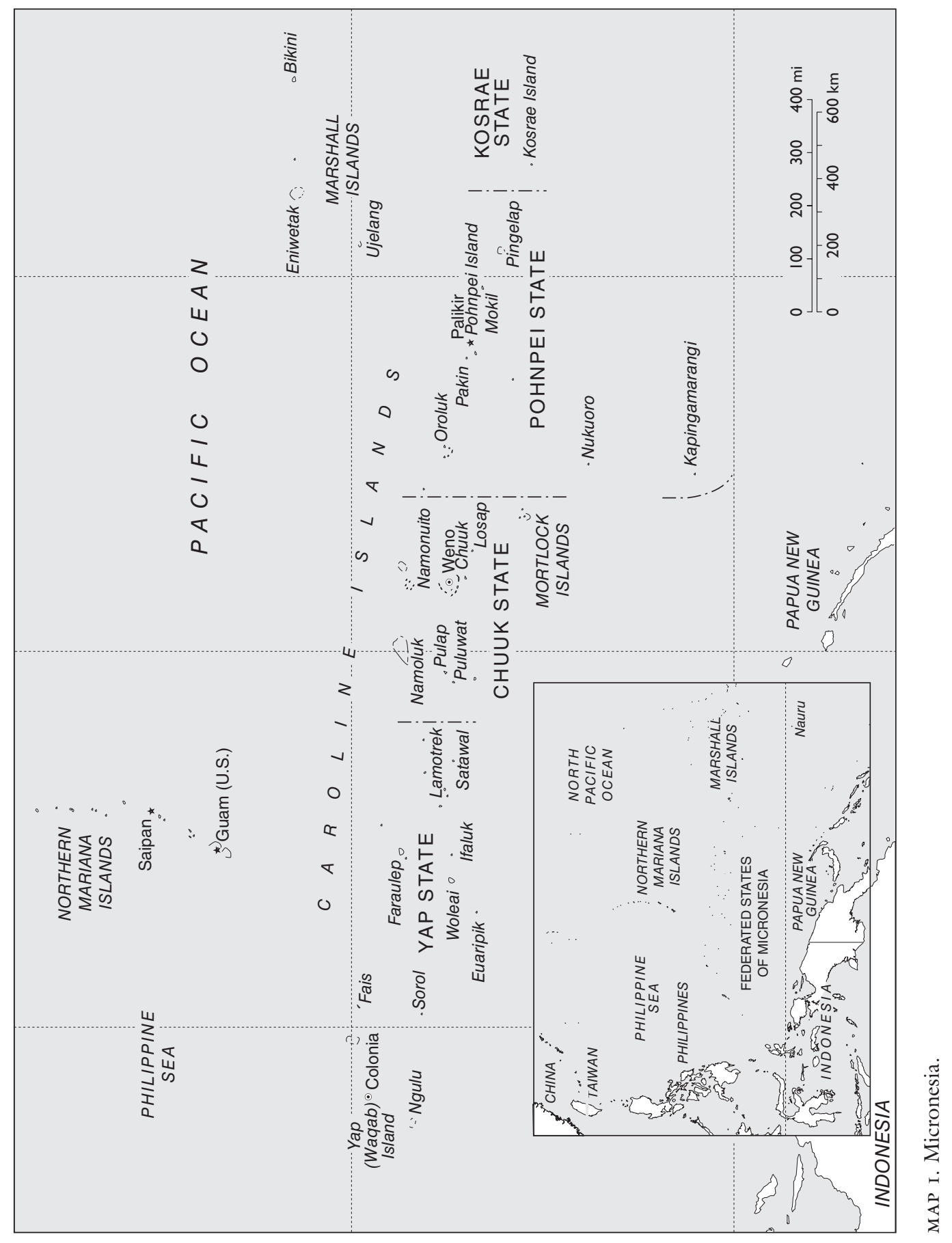




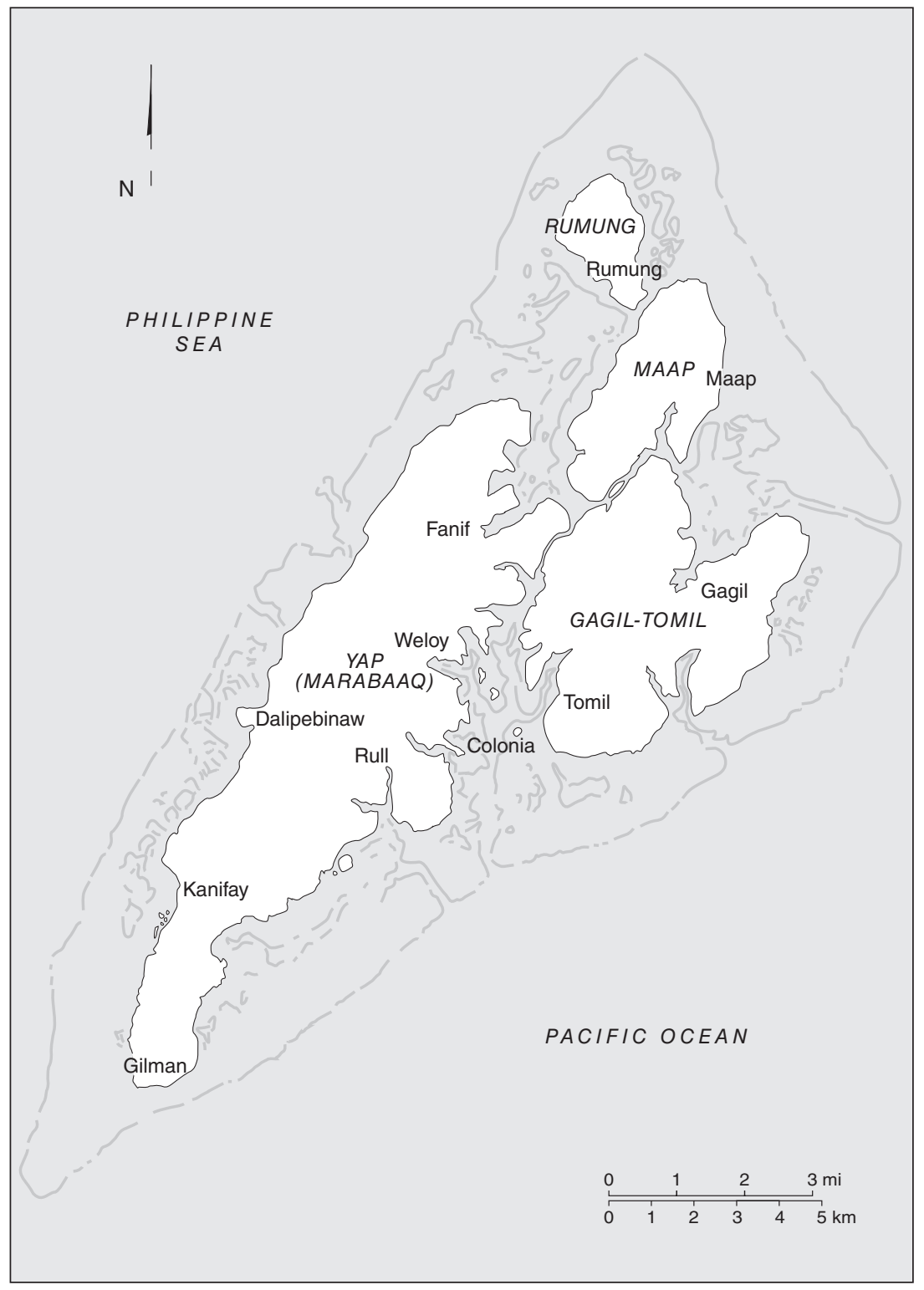

MAP 2. Yap. 